\title{
Maternity Leave in ENT: Sharing experience
}

\section{Introduction}

The process of organising maternity leave $(\mathrm{ML})$ and return to work (RtW) can be daunting, especially where the trainee is concerned that training may be compromised (e.g.. by leaving the on-call rota)

\section{Employees' rights - you are entitled to:}

- Maternity leave (52/52 total, must take min. $2 / 52)$

- Paid time off for antenatal care (midwife/doctor's appointments/scans/antenatal classes)

- Maternity pay or maternity allowance

- Protection against unfair treatment, discrimination or dismissal

- Accrued annual leave including public holidays

- Fixed term contracts - must be extended to allow full 52/52 ML if contract due to end after $11 / 52$ before estimated date of delivery (EDD)

- Rotational trainees - have the right to return to the same or the next placement

\section{Maternity Pay (MP) - 3 types}

- Statutory (SMP):

- Entitled to SMP If you have $12 / 12$ continuous NHS service by 11 weeks before EDD and intend to RtW for a minimum of $3 / 12$

- $8 / 52$ full pay

- $18 / 52$ half pay

- 26/52 unpaid

- Occupational (OMP):

- Entitled to OMP if at least 26 weeks of continuous employment with the same employer at 15 weeks prior to EDD

- 8/52 full pay (less SMP or MA receivable)

- $18 / 52$ half pay + flat rate SMP (f145.18) (or average weekly earnings, whichever lower), providing total does not exceed full pay

- $13 / 52$ unpaid

- Maternity Allowance (MA):

- If above conditions not met, e.g. 12/12 NHS service but $<26 / 52$ at current trust, can claim MA + SMP

- Claim via Gov.uk or Job Centre Plus

Keep in touch days (KIT)

- Take up to 10 in total, must agree dates and duties beforehand (best done in writing)

Supervised clinical sessions or courses/training days

- Paid at base daily rate minus usual tax/NI/pension minus any MP due on that day - consider financial implications, take close to RtW date

\section{Paternity Rights}

- Entitled to unpaid time off for 2 antenatal appointments

- Paternity leave - eligible for $2 / 52$ paid leave (if $>12 / 12$ continuous NHS service), usually starts the day after baby is born (but can defer as long as taken within first 8/52)

- Now entitled to share parental leave between both parents

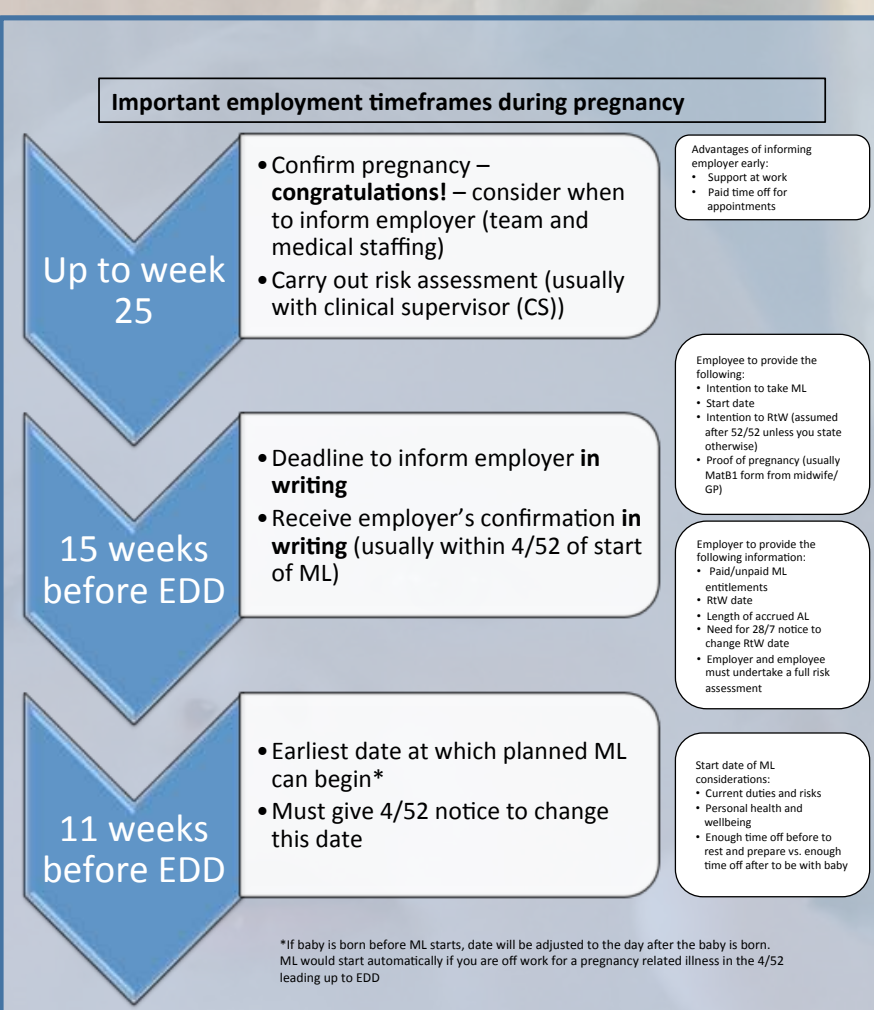

Pearls of wisdom from other trainees

- Check trust maternity guidance for local policies (trust website)

- RtW hours ideally prior to starting ML and discuss with deanery - it can take time to organise funding

- Boost income during qualifying weeks (average weekly income during 18-25/40) to improve overall MP e.g. in-house locums

- Consider requesting MP to be averaged and paid over $12 / 12$ rather than a reducing amount (must be agreed in advance, not all trusts will agree but should!)

- Organisations will often reduce fees during $\mathrm{ML}$ - must contact them in advance as not usually able to claim retrospectively (e.g. BMA/GMC/ISCP/RCS/MDU/MPS)

- Ensure both your trust and your deanery know your correct ML dates to ensure correct CCT date and pay

- Discuss with CS ways to ensure your wellbeing in theatre - sit to operate, planned breaks during long cases, hydration

- Try to get ISCP/surgical logbook up to date prior to ML so you are not worrying about this for ARCP when you RtW

- Think carefully before planning to write papers/take exams during $\mathrm{ML}$ - may be the last thing you can actually manage

- Ask other trainees when they came off the on-call rota

\section{Useful contacts/sources of information}

- Ask others who have recently been through the process

- BMA helpline: 03001231233 for individual advice

- BMA guidance:

https://www.bma.org.uk/advice/work-life-support/workingparents

- NHS Handbook: http://www.nhsemployers.org/tchandbook

- RCS Pregnancy and Maternity guidance booklet: http://surgicalcareers.rcseng.ac.uk 